\title{
Complex VATS segmentectomy: S8 segmentectomy
}

\author{
Ilies Bouabdallah \\ Department of Thoracic Surgery, Saint Joseph Hospital, Marseille, France \\ Correspondence to: Ilies Bouabdallah. Department of Thoracic Surgery, Saint Joseph Hospital, Marseille, France. Email: ilies.bouabdallah@gmail.com.
}

\begin{abstract}
Nowadays, lung sparing resections are more and more performed and thoracic surgeons should be well aware of operative technics for all kinds of segmentectomy. Despite the fact that there is no typical infra lobar anatomical resection, S8 segmentectomy is one of the most difficult lung segmentectomies because of the highly variable peripheral pulmonary anatomies and the difficulty of identifying the intersegmental plane. In case of intentional segmentectomy for early-stage lung cancer, multidisciplinary team and innovation are often required to ensure oncological safety: preoperative localization of the target lesion for adequate margins $+3 \mathrm{D}$ reconstructions for operative planification + indocyanine green (ICG) with fluorescent camera for intersegmental plane + frozen section on lymph node and margins. Regarding the operative technic, good exposure is mandatory to perform with good oncological rules this challenging procedure. Minimally invasive surgery is now the gold standard rather than the open thoracotomy. The multi-port access is helpful in VATS but this operation can be done with uniportal approach if the surgeon masters it. As there is no S7 on the left side, the left S8 segmentectomy is more often proposed than on the right side. We describe here the technique of the total multiport VATS left S8 lung segmentectomy.
\end{abstract}

Keywords: VATS; lung segmentectomy; lung cancer; thoracic surgery

Received: 20 May 2021; Accepted: 24 August 2021; Published: 20 October 2021.

doi: $10.21037 /$ jovs-21-26

View this article at: https://dx.doi.org/10.21037/jovs-21-26

\section{Introduction}

Within the scope of lung parenchyma preservation, thoracic surgeons are more frequently practicing lung segmentectomy. Several indications exist for this procedure:

* Regarding benign diseases or metastases when the localization is not in favor of a wedge resection.

* Regarding primary lung cancer, patients will be given a segmentectomy with radical lymph node dissection in two different scenarios:

- Patients with good respiratory function and a small lesion (cT1a-bNOM0): the chosen option may be a segmentectomy over a lobectomy if tumor's localization is anatomically suitable with safe margins and if examination $\mathrm{n}$ frozen section of N1 lymph nodes is negative (to eliminate an evident lymph node involvement). It is an intentional segmentectomy.

- Patients with limit respiratory function and a small lesion (cT1a-bN0M0): the chosen option may be a segmentectomy for a local treatment because they cannot benefit from a lobectomy. It is a compromised segmentectomy.

The S8 segmentectomy is a very complex procedure that can be ambitious mostly because of variations in the anatomy and the complexity of the intersegmental plane (1). Moreover, it's an intervention mainly practiced on the left side because of the anatomy of the lung with a mediobasal segment (S7) only on the right side.-

Here we present a step-by-step left anteriobasal segmentectomy (S8) with a high-quality video and tips and tricks.

\section{Surgical techniques (Video 1)}

\section{Port's placement}

There are many possibilities of port positioning, the technique mainly depends on the surgeon's preference. The authors have chosen for all kinds of VATS left lung resection 


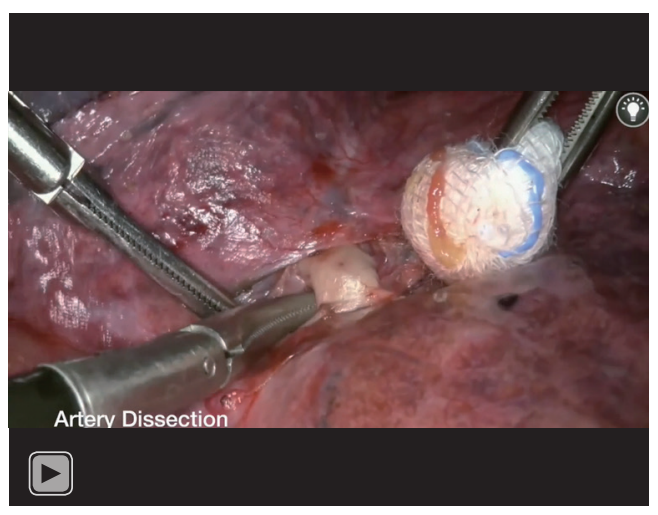

Video 1 Operative technic of a left VATS S8 lung segmentectomy.

a unique technique with 4 ports. We think that the number of trocars is not a real concern regarding the value of good exposure for qualitative segmentectomy. We used a total port approach without utility incision. On the left side, we prefer operating from the front with the assistant in the back.

For the assistant, we insert the scope in the posterior axillary line in the eighth intercostal space, and for exposure a $10 \mathrm{~mm}$ trocar in the posterior axillary line in the sixth intercostal space.

The surgeon uses his left hand with the $10 \mathrm{~mm}$ trocar in the anterior axillary line in the fourth intercostal space, and his right hand with a large-sized trocar in the anterior axillary line in the sixth intercostal space.

\section{Initial inspection}

First, a full evaluation of the entire thoracic cavity is done: the pleura, the quality of the parenchyma (emphysema), the fissures opening (Walker's classification), the anatomical disposition and the exact tumor's localization. Authors use peanuts to mobilize the lung and never grasp the remaining parenchyma to avoid air leak.

\section{Radical lymph node dissection}

Lymph nodes are removed at the beginning of the intervention. It enables to clear the broncho-vascular elements and makes the lung resection easier. The lymph nodes dissection is performed all around the hilum (station $10 \mathrm{~L}$ ), in mediastinal sites (station $8 \mathrm{~L}$ and $9 \mathrm{~L}$, station 7 , station 5 and 6) and inside the fissure (station 11L). Lymph nodes located at the arterial division of A8 and A9-10 (station 12L) must be sent for frozen section examination in case of intentional segmentectomy.

\section{Artery dissection}

As well as a lower lobectomy, we advance to the pulmonary artery in the middle portion of the fissure. After identifying the pulmonary artery, the anterior part of the fissure is opened with energy or stapler depending on the thickness.

Without help of preoperative 3D CT images, it can be difficult to recognize branching of A8a et A9a. To identify them accurately, A8 is sufficiently exposed near the peripheral direction. If A8 is still difficult to be defined, only the ventral branch is cut first, which must not be A9a (2). In our video we used Fluorescence to identify A8a and A8b before stapling.

\section{Bronchus dissection}

Cutting A8 reveals $\mathrm{B} 8$ which runs behind $\mathrm{A} 8$. The $\mathrm{B} 8$ is dissected carefully to avoid damaging V6 and V8 running behind it. Bronchus is then stapled after a ventilation test (to verify S9-10 and S6 good ventilation). Lifting the distal B8 stump exposes V8 running towards the stump.

\section{Veinous dissection}

The inferior pulmonary vein does not have to be exposed within the scope of a S8 segmentectomy (3).

In addition, as V8 is usually unidentical to a superior basal pulmonary vein, it should not be cut. After we divided the segmental bronchus, we easily recognized the anterior basal segmental vein (V8) because it was located right behind the $\mathrm{B} 8$.

\section{Intersegmental plane}

After broncho-vascular dissection, indocyanine green (ICG) is injected into a peripheral vein and observation of the lung start using an infrared thoracoscope (4).

Afterwards, the ICG distributed area became green on the infrared monitor, and the ICG defected area remained in regular color. We can visualize the intersegmental border with or without fluorescence. Then, using electrocautery, we mark the transitional zone on the visceral pleura and divide the lung parenchyma using staplers at the origin of this position.

Attention should be taken that the bronchial stump stays remote in the operative specimen. 
More, to ensure sufficient lateral margins, authors recommend sending the entire specimen for frozen section examination.

\section{Comments}

The main obstacles in minimally invasive segmentectomies are found in locating the target lesion (often very small and not visible), identifying the anatomical elements (with many variations) and demarcating the intersegmental plane.

Concerning the identification of the lesion, surgeons can use various help in order to have a precise localization imperative to ensure correct safety margins and limit local recurrences. One of the options, is to put a radiological coil near the lesion (not inside the lesion, to preserve the pathological examination) just before the intervention. Both procedures have to be synchronized, thanks to the implication of an interventional radiologist available and a good logistics.

Another option is to inject bronchoscopic dye, like ICG, inside the targeted location just before the intervention: the surgeon can start the surgery by inserting the camera and identify the lesion with a near-infrared imaging system (note that location by using intrabronchial injection of methylene blue is feasible but less accurate).

Fluorescence is also necessary for anatomical variations and intersegmental plane. The identification of S8 goes by clamping A8 and using a systemic injection of ICG. Indeed, all areas which did not appear green correspond to segments to resect. In case of insufficient margins, lung resection must be enlarged. It is also essential that, after removing the specimen, vascularization of remaining segments should be insured thanks to ICG. If fluorescence is unavailable, the intersegmental plane can be identified during a ventilation test but this alternative is less precise especially for patients with emphysema.

To provide the best oncological outcomes, we must dissect lymph node of the remaining segments (5). Note that in case of invaded lymph node at the frozen section examination (for an intentional segmentectomy), the procedure will be converted to a lobectomy.

Finally, we strongly recommend using $3 \mathrm{D}$ reconstruction upstream to apprehend anatomical variations and avoid misapprehension of pulmonary structures. Without this tool, dissection has to be conducted as low as possible so all branches are identified before stapling.

Precautions must be taken regarding the arterial branches. Effectively, a low A6 can be confused with an A9-
10. Moreover, instead of A8 and A9-10, a branching pattern with A8-9 and A10 or A8, A9 and A10 can be encountered. The division of $\mathrm{A} 8 \mathrm{a}$ and $\mathrm{A} 9 \mathrm{a}$ is sometimes complex, such as A8a branching from A9-10 and A9a from A8. To avoid any of these confusions, the $3 \mathrm{D}$ reconstruction is a complete tool allowing a dynamic navigation through arteries, veins and bronchi, to know the volume of the segments to be resected and to visualize safety margins.

\section{Conclusions}

As there is no S7 on the left side, the left S8 segmentectomy is easier and more often proposed than on the right side. However, variations in anatomical landmarks require value of innovations and multidisciplinary team in this challenging anatomical infra-lobar resection. The authors recommend for oncological safety of this difficult intentional lung segmentectomy the use of preoperative localization $+3 \mathrm{D}$ reconstructions + fluorescent camera + frozen section.

\section{Acknowledgments}

Funding: None.

\section{Footnote}

Provenance and Peer Review: This article was commissioned by the Guest Editor (Michel Gonzalez) for the series "VATS Segmentectomy" published in Fournal of Visualized Surgery. The article has undergone external peer review.

Peer Review File: Available at https://jovs.amegroups.com/ article/view/10.21037/jovs-21-26/prf

Conflicts of Interest: The author has completed the ICMJE uniform disclosure form (available at https://jovs. amegroups.com/article/view/10.21037/jovs-21-26/coif). The series "VATS Segmentectomy" was commissioned by the editorial office without any funding or sponsorship. The author has no other conflicts of interest to declare.

Etbical Statement: The author is accountable for all aspects of the work in ensuring that questions related to the accuracy or integrity of any part of the work are appropriately investigated and resolved. All procedures performed in this study were in accordance with the ethical standards of the institutional and/or national research committee(s) and with the Helsinki Declaration (as revised 
in 2013). Written informed consent was obtained from the patient for publication of this manuscript and any accompanying images and videos.

Open Access Statement: This is an Open Access article distributed in accordance with the Creative Commons Attribution-NonCommercial-NoDerivs 4.0 International License (CC BY-NC-ND 4.0), which permits the noncommercial replication and distribution of the article with the strict proviso that no changes or edits are made and the original work is properly cited (including links to both the formal publication through the relevant DOI and the license). See: https://creativecommons.org/licenses/by-nc-nd/4.0/.

\section{References}

1. Nomori H, Okada M. Illustrated anatomical

doi: $10.21037 /$ jovs-21-26

Cite this article as: Bouabdallah I. Complex VATS segmentectomy: S8 segmentectomy. J Vis Surg 2021;7:49.
Segmentectomy for Lung Cancer. Tokyo: SpringerVerlag, 2012.

2. Seguin-Givelet A, Brian E, Grigoroiu $M$ et al. Thoracoscopic S8 segmentectomy. J Vis Surg 2018;4:196.

3. Miyajima M, Watanabe A, Uehara M, et al. Total thoracoscopic lung segmentectomy of anterior basal segment of the right lower lobe (RS8) for NSCLC stage IA (case report). J Cardiothorac Surg 2011;6:115.

4. Guigard S, Triponez F, Bédat B, et al. Usefulness of nearinfrared angiography for identifying the intersegmental plane and vascular supply during video-assisted thoracoscopic segmentectomy. Interact Cardiovasc Thorac Surg 2017;25:703-9.

5. Thomas PA. Lymph node dissection during sublobar resection: why, when and how? J Thorac Dis 2018;10:S1145-50. 